\title{
A STUDY ON VISUAL IMPAIRMENT AND FUNCTIONAL NEED ASSESSMENT OF PATIENTS ATTENDING OUTPATIENT CLINIC AT A REGIONAL EYE HOSPITAL FOR VISUAL HANDICAP CERTIFICATES
}

\author{
K. S. Rajiv Krishna
}

${ }_{1}^{1}$ Associate Professor, Department of Ophthalmology, Andhra Medical College/Government Regional Eye Hospital, Visakhapatnam, Andhra Pradesh, India.

ABSTRACT
BACKGROUND
Blindness is one of the major health problems in India. It affects not only the individual but also his entire family and society. Some
ocular diseases are treatable; others are not. Non-treatable causes lead to permanent visual handicap. Until recently, blind/vision-
impaired people did not have proper education, counselling and job opportunities to integrate themselves into the society. We
wanted to evaluate the causes of visual impairment, conduct disability assessment, and assess the functional needs of blind/vision-
impaired people.

\section{METHODS}

A total of 350 patients attending the outpatient department at Regional Eye Hospital, Visakhapatnam, Andhra Pradesh for visual impairment certificates were taken randomly for the study. The percentage of disability was calculated based on the government guidelines for the evaluation of visual disability and procedure of certification.

\section{RESULTS}

Among the 350 patients, majority were $100 \%$ blind (category 3 \& category 4 ). 70 patients had visual impairment of $40 \%$, followed by 62 patients who are one eyed. The cause of blindness was hereditary in 105 cases, followed by disease and infection in 87 cases and accident in 77 cases. Majority of them were advised assistive and augmentative devices. Blind sticks and Low Vision Aids were advised to 175 patients and Braille equipment for 130 patients.

\section{CONCLUSIONS}

Assessment of visual impairment, identification of major causes, advising assistive and augmentative devices, and fulfilling the general needs of visually challenged persons, can bring a remarkable change in their life styles and thereby enhance their contribution to the society.

HOW TO CITE THIS ARTICLE: Krishna KSR. A study on visual impairment and functional need assessment of patients attending outpatient clinic at a regional eye hospital for visual handicap certificates. J. Evolution Med. Dent. Sci. 2019;8(16):1273-1279, DOI: $10.14260 /$ jemds/2019/284

\section{BACKGROUND}

India has a large blind population. According to the International Agency for the Prevention of Blindness (IAPB) by the year 2015, India had a prevalence of $4.63 \%$ of Moderate and Severe Visual Impairment with visual acuity $<6 / 18$ to $\geq 3 / 60$. $^{1}$ Visual impairment disability in India is categorized based on its severity. Percentages are accorded as proposed by a subcommittee constituted by the Ministry of Social Justice and Empowerment in 1999. The categories of visual disability are notified in the Gazette of India, extraordinary, 2001 and are followed all over the country. ${ }^{2}$ There has been an evolutionary process in changing attitudes regarding the disabled and blindness around the globe. ${ }^{3}$ In olden days the attitude was of disregard, rejection, isolation, and abuse, however, recently the attitude changed to pity and benevolence. 4

'Financial or Other Competing Interest': None.

Submission 08-12-2018, Peer Review 21-03-2019,

Acceptance 28-03-2019, Published 22-04-2019.

Corresponding Author:

Dr. K. S. Rajiv Krishna,

2-45-14/1, GF 101

Veitla Park View Apartment,

MVP Colony. Sector 11,

Visakhapatnam-530017, Andhra Pradesh, India.

E-mail: ksrk9999@gmail.com

DOI: $10.14260 /$ jemds $/ 2019 / 284$

\section{(c) (i) $(9)$}

Currently, there is a positive attitude towards the disabled including the blind and this becomes more important considering the fact that country incurs a huge expenditure directly in supporting and indirectly through loss of economic productivity of the disabled. ${ }^{5}$ Disability is any restriction or lack (Resulting from impairment) of ability to perform an activity in the manner or within the range considered normal for a human being. Handicap is a disadvantage for a given individual resulting from an impairment or disability that limits or prevents the fulfilment of a role that is normal (Depending on age, sex, social and cultural factors) for that individual. The concept of handicap also includes the role of the society in creating barriers and limiting opportunities for people with disabilities. ${ }^{6}$

\section{Aims and Objectives}

1. To evaluate causes of visual impairment

2. Conduct disability assessment

3. Assess the functional needs of blind/visionimpaired people at our hospital.

4. Analyse number of assistive and augmentative devices distributed to the visually handicapped persons

5. To evaluate counselling and guidance given to blind/vision-impaired people at our hospital.

\section{METHODS}

We performed a retrospective descriptive study. Patients obtaining visual disability certificates at our hospital during 
1st June 2017 to 31st May 2018 were retrospectively analysed. Records of patients who were issued visually handicapped certificates were identified and included in the study. Cause of blindness, percentage of visual disability, and purpose of visual disability certificate were noted after detailed examination which included slit-lamp examination, direct ophthalmoscopy, indirect ophthalmoscopy, slit-lamp bio microscopy with 78D lens, applanation tonometry, Humphrey visual field analysis wherever necessary and feasible.
Routinely, the data related to the purpose of the visual handicap certification is mentioned in the blindness register of the hospital. The proforma7 issued by the Government of Andhra Pradesh for visual impairment assessment and functional need assessment was followed in this study and is shown below. The individuals were provided with unique ID Number (17 Digits) by the Government. The data were entered into database and analysed using MS excel software.

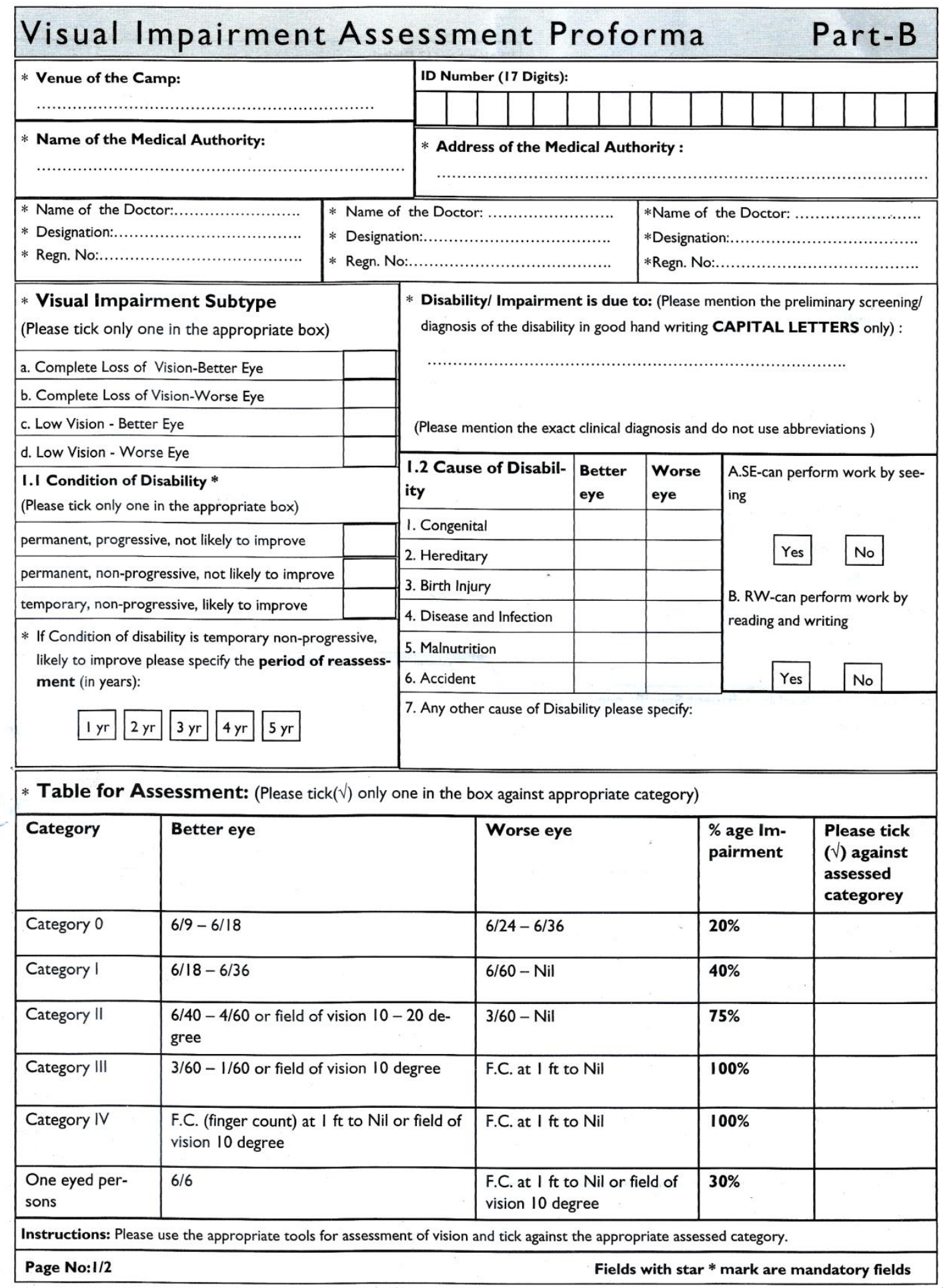

Figure 1. Proforma for Assessing the Visual Impairment 


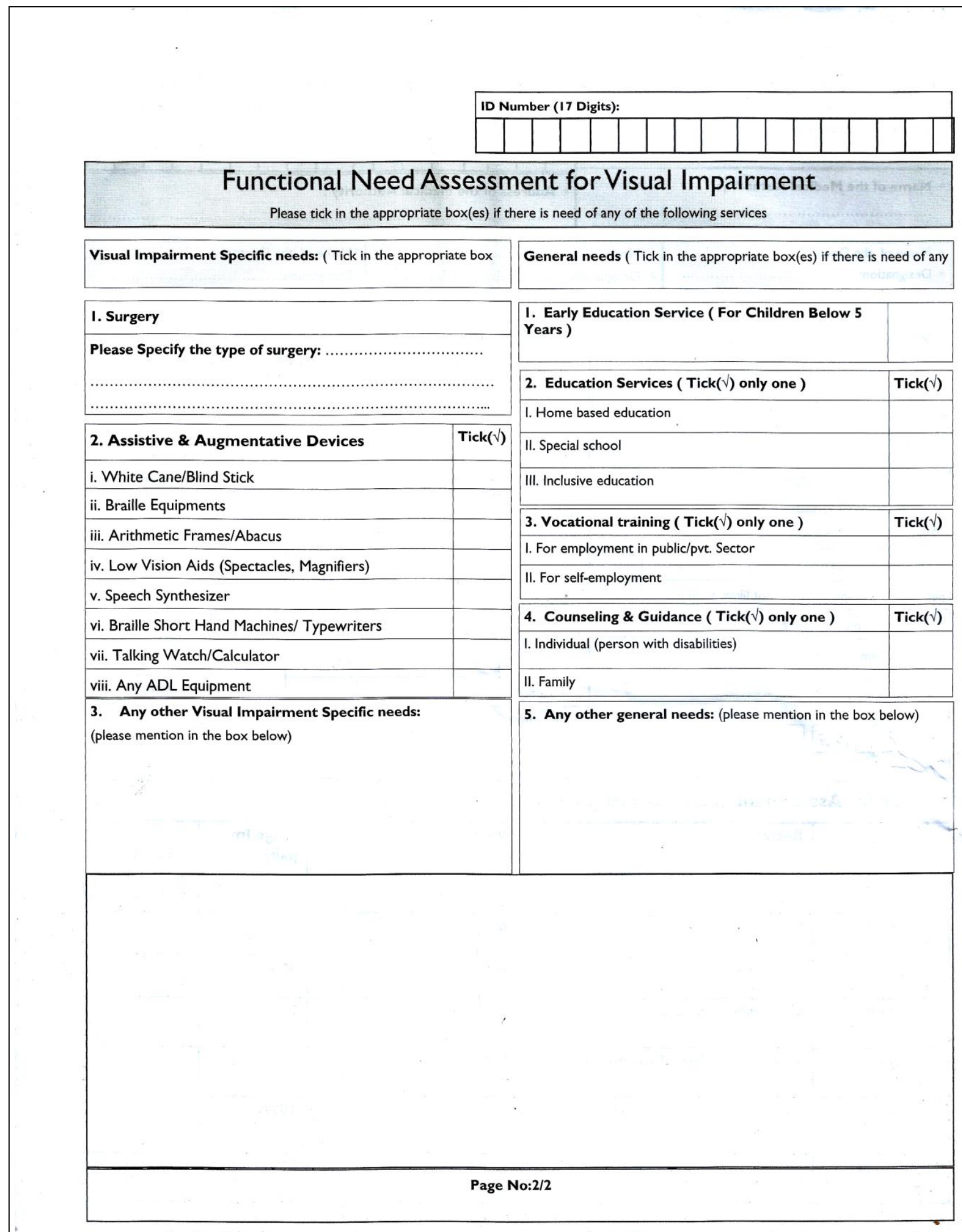

Figure 2. Proforma for Assessing the Functional Needs in Visually Impaired

\section{RESULTS}

In 350 cases analysed, 119 patients (34\%) were in 16-40 years age group, 101 patients (29\%) in 41-65 years age group, 70 patients (20\%) in paediatric age group and senior citizens constituted $17 \%$. Males were $57 \%$ and females $43 \%$ in the study. $66 \%$ were from rural background and $34 \%$ from urban areas. $28 \%$ were farmers, $22 \%$ were workers and $20 \%$ were employees. Hereditary causes like retinitis pigmentosa 
were found in $30 \%$ of cases followed by diseases and infections in $25 \%$, accidents in $22 \%$ and congenital causes were found in $18 \%$ of the cases. $68 \%$ of the cases had permanent, non-progressive, not likely to improve type of disability. About $50 \%$ of the cases had $100 \%$ disability $(28 \%$ in category 4 and $22 \%$ in category 3 ). About $18 \%$ of patients had visual impairment in one eye.

Surgery was advised in $30 \%$ of cases. Majority of them had undiagnosed cataracts. Cataract surgery was essential for both best corrected visual acuity assessment and posterior segment analysis. Blind sticks and Low Vision Aids were advised to 175 patients and Braille equipment for 130 patients. $28 \%$ ( 98) of the cases were advised vocational training of which $30 \%$ was for employment in public/private sector and $70 \%$ for self-employment. The main purpose of obtaining the certificates was for financial reasons (54\%) in this study. The results are displayed in the following graphs.
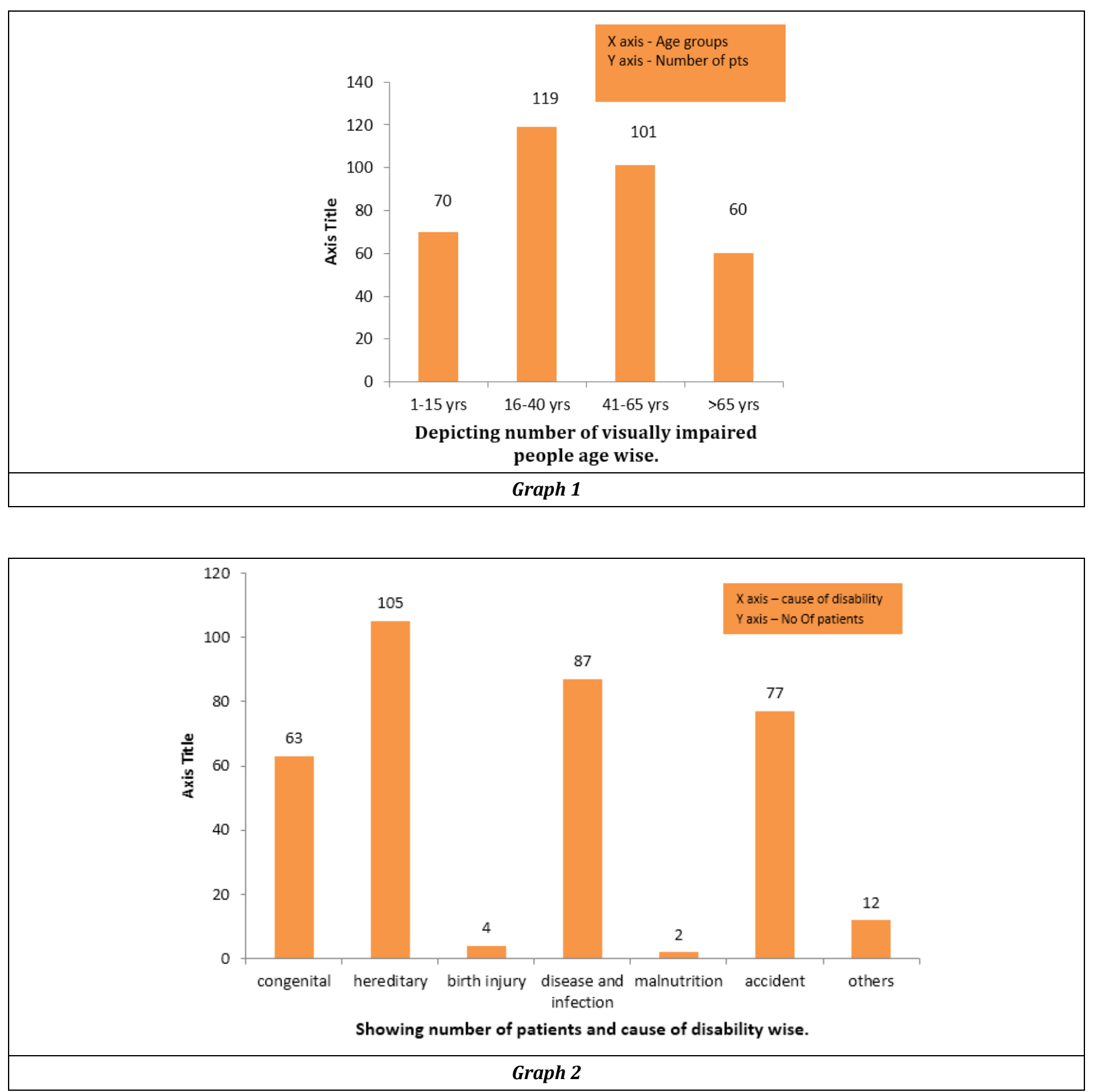

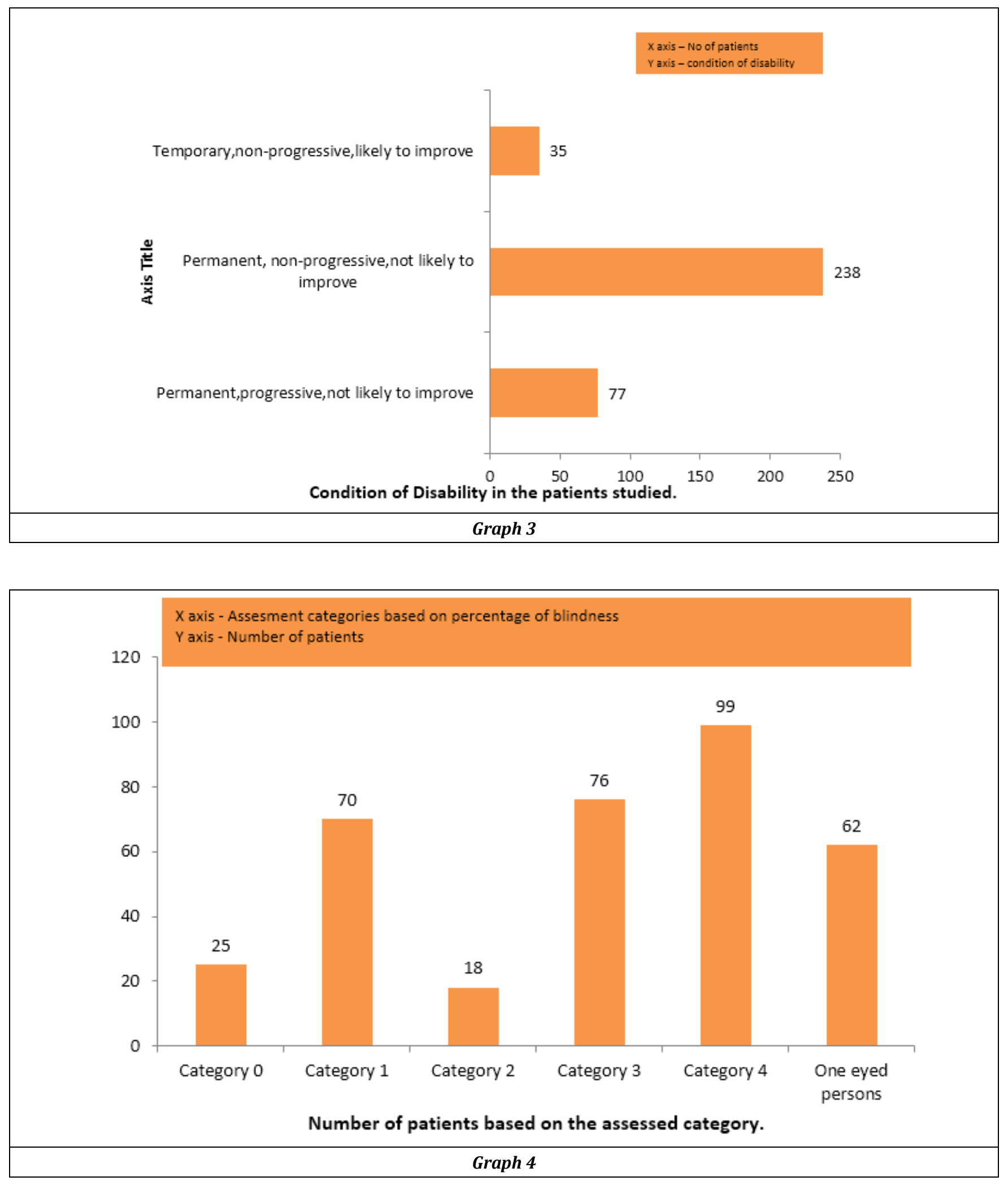


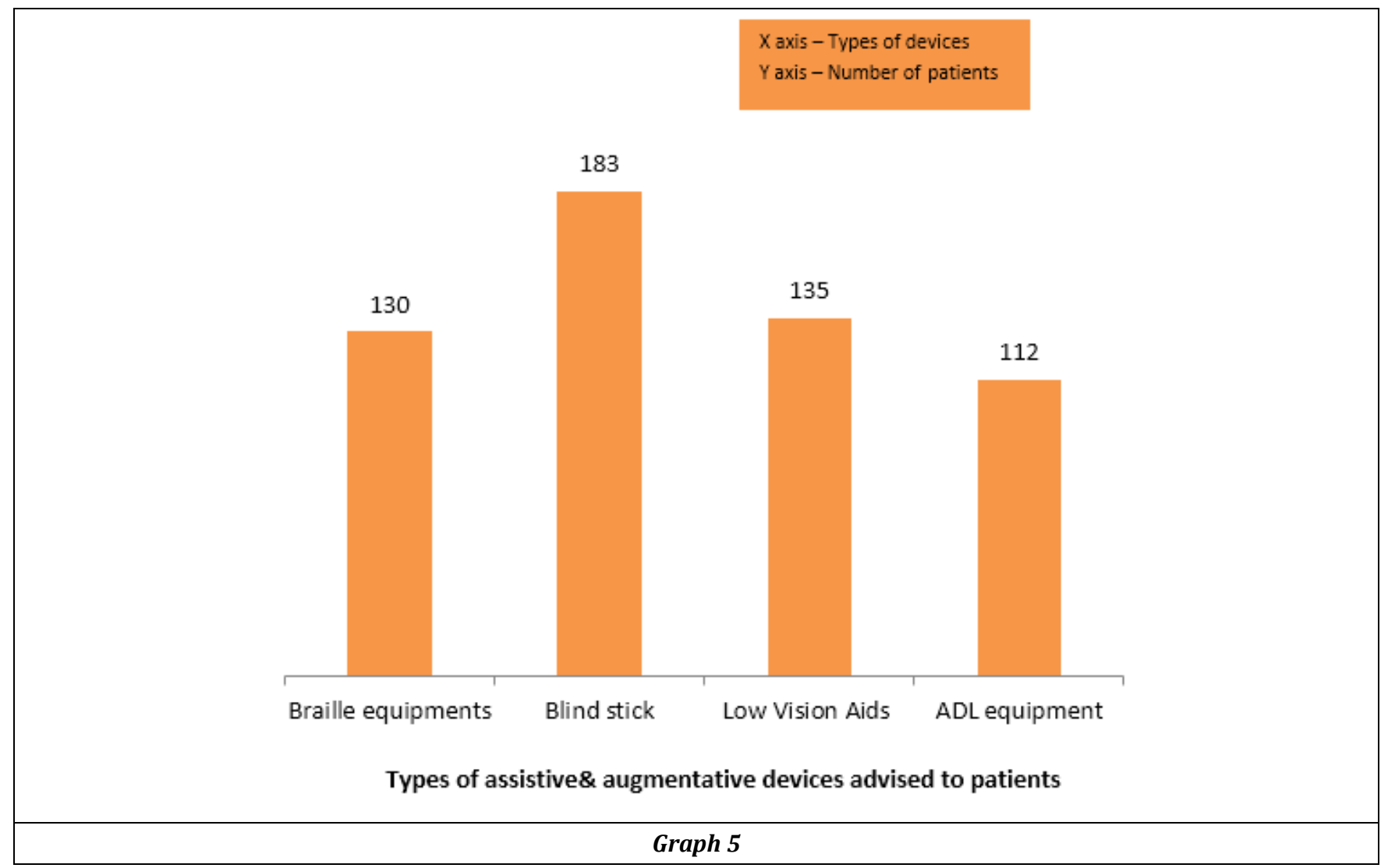

\section{DISCUSSION}

India which is the second largest country in the world in terms of population unfortunately also has large number of blind people. Several factors play major role for large prevalence of blindness in ourstate ${ }^{8}$. Various ocular pathologies can cause visual impairment. This can lead to disability and finally handicap for the given individual. Visually handicap people have to face huge challenge to survive in the society.

Visual impairment in general affects the following four main functional areas 4 :

1. Orientation/Mobility,

2. Communication,

3. Activities of Daily Living (ADL) and

4. Sustained Near Vision Task.

Early intervention and special education can balance the negative effects of visual impairment. In many cases environmental adaptations, vision training, follow up for ensuring compliance, coordinating with stakeholders, removing myth and misconception and counselling would help in empowering the individual and/or enhancing functional residual vision.

The effect of low vision is not same for all people and the following assessment needs to be compiled for each individual before embarking upon the decision of assistive devices. ${ }^{4,9}$

- Extent of vision: Near and distance visual acuity.

- $\quad$ Size of the visual field [if relevant].

- Effect of light and glare.

- Extent of recognition and naming of colours.

- Extent to which contrast affects their activities.
- Extent of use of vision for different activities and purpose in the environment.

- Extent to which a person sees and recognizes an object depends, amongst other on: Familiarity of the object; light; size; distance; contrast; colour; detail or simplicity of the object.

- Age, socioeconomic conditions, literacy status, and level of motivation.

In this study, majority of the patients were in the age group of $16-40$ years (34\%) and 41-65 years (29\%). Patil et al ${ }^{10}$ in their study had similar results. More registrations in these age groups is probably related to requirement of visual handicap certification for educational and employment purposes. Males outnumbered females in the study. Joshi et al $^{11}$ had similar observations. This is probably due to increased outdoor activities of males or males may have more need of certification. Rural population was more than urban possibly due to more prevalence of avoidable blindness in rural India and probably due to introduction of populist pension schemes by various governments. Farmers and labourers were registered more in the study as their occupations are more hazards prone. Hereditary causes like retinitis pigmentosa, various ocular diseases and trauma were major causes of disability in this study. Other similar studies reported disease specific causes for visual impairment. Most of the patients in this study had permanent, non-progressive, not likely to improve condition of disability. Bunce et $\mathrm{al}^{12}$ in her study had more number of patients with permanent visual impairment and no ongoing treatment.

Majority of the cases had $100 \%$ disability probably ours being a tertiary eye care centre. Main purpose of obtaining this certificate in my study is for pension purpose. Patients 
who had undiagnosed cataracts underwent surgery at our institute. Depending upon the functional need blind sticks, Braille equipment, Low vision aids and ADL $^{13}$ (Activities of daily living) equipment were advised. General needs of the patients like education, vocational training, counselling and guidance were addressed depending upon the situation.

\section{CONCLUSIONS}

Visual impairment is a big challenge to the individuals, their families, and to society as a whole, considering the fact that India has huge blind population. ${ }^{14}$ We need to focus on genetic counselling and discourage consanguineous marriage to prevent congenital anomalies. School children screening is a must to identify and treat refractive error and vitamin deficiencies ${ }^{15}$ in those children. Road safety rules should be strictly implemented as road traffic accidents are becoming one of the major causes of blindness.

These types of studies ${ }^{16}$ help in improving visual impairment assessment and functional need assessment for the blind people. They also help us to know various sociodemographic factors causing blindness. Diseases causing blindness in the community can also be analysed.

According to a guideline by the 'Ministry of Social Justice and Empowerment' of 'Government of India', the minimum degree of disability should be $40 \%$ for an individual to be eligible $^{2}$ for any concessions or benefit. Reviewing disability guidelines from time to time, and proper assessment help the patients to get accurate visual handicap certificates and thereby benefits linked to them.

\section{ACKNOWLEDGEMENTS}

I sincerely thank all the teaching faculties of the Institute for their help. My gratitude to the patients and attendants with whom we personally interacted.

\section{REFERENCES}

[1] Vision atlas of International Agency for the Prevention of Blindness (IAPB), launched on world's sight day (12 ${ }^{\text {th }}$ October 2017).

[2] Ministry of Social Justice and Empowerment: Guidelines for evaluation of various disabilities and procedure for certification. The Gazette of India extraordinary. Part 1: Section 1. No 154. Notification dated 1st June, 2001.

[3] Sood S, Nada M, Nagpal RC. Psychosocial implications of blind child. Indian J Community Med 2004;29:94-5.
[4] Jose R, Sachdeva S. Community rehabilitation of disabled with a focus on blind persons: Indian perspective. Indian J Ophthalmol 2010;58(2):137-42.

[5] Köberlein J, Beifus K, Schaffert C, et al. The economic burden of visual impairment and blindness: a systematic review. BMJ Open 2013;3(11):e003471.

[6] Park K. Park's Textbook of Preventive and social medicine. 24th edn. Jabalpur, India: M/s Banarsidas Bhanot 2017.

[7] Women development, Child Welfare \& Disabled Welfare (DW) Department. Government of Andhra Pradesh. G.O.Ms.No.31. 01-12-2009.

[8] Dandona L, Dandona R, Srinivas M, et al. Blindness in the Indian State of Andhra Pradesh. Invest Ophthalmol Vis Sci 2001;42(5):908-16.

[9] Keeffe J. Assessment of low vision in developing countries. Book 1 and 2: "Low vision kit". Geneva: WHO and Australia: Low vision project international, 1995.

[10] Patil B, Pujar C, Manasa CN, et al. Study of causes of visual handicap amongst patients attending outpatient department for visual handicap certification in a medical college of Bagalkot district of Karnataka, India. Medica Innovatica 2015;4(2):13-6.

[11] Joshi RS. Causes of visual handicap amongst patients attending outpatient department of a medical college for visual handicap certification in central India. 2013;1(1):17-9.

[12] Bunce C, Evans J, Fraser S, et al. BD8 certification of visually impaired people. British Journal of Ophthalmology 1998;82(1):72-6.

[13] Kempen GI, Ballemans J, Ranchor AV, et al. The impact of low vision on activities of daily living, symptoms of depression, feelings of anxiety and social support in community-living older adults seeking vision rehabilitation services. Quality of Life Research 2012;21(8):1405-11.

[14] Murthy GV, Gupta SK, Bachani D, et al. Current estimates of blindness in India. British Journal of Ophthalmology 2005;89(3):257-60.

[15] Hornby SJ, Adolph S, Gothwal VK, et al. An evaluation of children in six blind schools of Andhra Pradesh. Ind J Ophthalmol 2000;48(3):195-200.

[16] Monga PK, Parwal BP, Rohatgi J, et al. Are current guidelines for categorization of visual impairment in India appropriate? 2009;57(6):423-6. 